\title{
My reminisces of interaction with Vikram Sarabhai
}

\author{
Govind Swarup* \\ National Centre for Radio Astrophysics, Pune 411 007, India
}

After working in the field of radio astronomy for two years in Australia and seven years in USA, I joined the Tata Institute of Fundamental Research (TIFR) at Mumbai in April 1963. I met Vikram Sarabhai in 1964 during his visit to TIFR. He invited me to visit the Physical Research Laboratory (PRL) in Ahmedabad to interact with its faculty and students. I went to PRL several times during the next three years. There I also gave talks on radio astronomy, the Kalyan Radio Interferometer and the Ooty Radio Telescope (ORT). I had many discussions with the faculty and students at PRL regarding research being carried out in several fields, such as cosmic rays, atmospheric sciences. I also recall discussions with U. R. Rao about his work on cosmic rays and solar wind. During one of my visits to PRL, Sarabhai described to me his plans for building capabilities for space research and communication in India. He had a clear vision about it. He also took me to visit the Indian Institute of Management in Ahmedabad that was founded by him. It was a great experience. I also visited two sites that were selected by him for establishment of the proposed Space Applications Centre (SAC) at Ahmedabad. I was also told then that it was planned to import a $45 \mathrm{ft}$ parabolic dish from Japan for microwave communication at the SAC. I told Sarabhai that it could be designed and built in India in a couple of years instead of being imported.

Sarabhai became the Chairman of the Atomic Energy Commission after the untimely death of Homi Bhabha in January 1966 in a plane crash at the Mont Blanc in the Swiss Alps. In 1965, Bhabha had approved the construction of the ORT that was proposed by me. During a visit to TIFR, Sarabhai asked me the details of the construction being done for the ORT that consisted of a $530 \mathrm{~m}$ long and $30 \mathrm{~m}$ wide parabolic cylindrical reflector being placed on a hill at Ooty. Sarabhai made several valuable comments that we considered.

In 1967, Sarabhai invited M. G. K. Menon, Yash Pal, I and Sitaram from TIFR to visit the Thumba Equatorial Rocket Launching Station (TERLS) where a rocket was being designed for launching in space. After we reached TERLS, Sarabhai introduced to us the teams that were designing various sub-systems of the rocket. Menon and Yash Pal visited the group that was designing the solid

\footnotetext{
*e-mail: gswarup29@gmail.com
}

state propellant for the rocket under the guidance of Vasant Gowrikar and others. They were very impressed by the work being done by the group. I interacted with Kalam who was designing the Nose Cone of the rocket. As I recall he had placed several posters on a wall in a hall describing the design of the Nose Cone being done by him and likely problems. I told him that he would certainly find solutions since he had already posed questions. He was also concerned about the effect of air turbulence on the Nose Cone. I described to him its role on large parabolic dishes used in radio astronomy. Sitaram who was an expert in the field of microwaves at TIFR offered help to the team designing communication equipment for the rocket at TERLS.

In early April 1968, Sarabhai planned to spend two weeks at Ooty for a vacation along with Mrinalini Sarabhai and his daughter Mallika Sarabhai. Sarabhai could not find a suitable accommodation at Ooty because of the summer rush. I was also not able to find it for them. Thereafter, Sardar Ujjal Singh, the Governor of Tamil Nadu, invited Sarabhai to stay at the Raj Bhawan at Ooty that he accepted after some hesitation because he generally avoided availing facilities by the Government for himself as he told me. After a few days he, Mrinalini Sarabhai and Mallika Sarabhai visited the site where the ORT was under construction. Sarabhai wanted to know its details that I described to him. The ORT was being constructed as a parabolic cylindrical reflector antenna of $530 \mathrm{~m}$ length and $30 \mathrm{~m}$ width that was being placed on a hill at Ooty with its north-south slope of $11^{\circ} 23^{\prime}$ same as its latitude, thus becoming parallel to the axis of rotation of the earth allowing its rotation for about 10 hours every day. I told Sarabhai that ORT was planned for lunar occultation observations for measuring angular sizes of radio galaxies with arc second resolution for the first time in radio astronomy and for other investigations. Stainless steel wires of $0.38 \mathrm{~mm}$ formed reflecting surface of the ORT. The parabolic cylindrical antenna consisted of 24 parabolic frames each of $30 \mathrm{~m}$ width that were mounted on 24 steel towers. Near the top of the hill three towers that mounted parabolic frames had been erected when Sarabhai visited the site. Few more were under erection by M/s Bridge of Roof of Kolkata. Considering its complexity Sarabhai asked me whether I had seen the movie Zorba the Greek. Zorba was always dreaming big 
projects but his schemes always failed because he had not considered details! Sarabhai told me to ensure that no accidents should take place during the construction of the ORT and gave few hints. I asked Mrinalini Sarabhai which colour should be painted for the ORT. She looked around, saw many eucalyptus trees at the site, and suggested to me the same as back of the eucalyptus leaves. We did that and ORT looked magnificent.

Sarabhai phoned me at $\sim 10$ PM on the night of 31 December 1968 and said 'Govind you have put me in a difficulty'. I asked him why. He told me that he had attended a meeting of the Scientific Advisory Committee of the Cabinet chaired by Mrs Indira Gandhi, the Prime Minister of India, earlier on that day. She asked the members as to what equipment are being imported that could be made in India. Sarabhai informed her that the Overseas Commission of India (OCS) was planning to import a $29.6 \mathrm{~m}$ (97 feet) antenna for the ARVI Satellite Communication Project that perhaps could be made in India. She told him to get it made by the DAE and asked him to submit a report in a month. Therefore in the night of 31 December 1968 Sarabhai asked me to attend a meeting in his office on 1 January 1969 at 9 AM. I told him that a New Year's party was taking place at our residence that would last till 3 AM. Sarabhai told me that the party would be over by $2 \mathrm{AM}$ and the meeting would take place at $10 \mathrm{AM}$ !

After some discussions in the meeting held on 1 January 1969 , Sarabhai asked me to submit a feasibility report in two weeks examining the possibility of manufacturing the $29.6 \mathrm{~m}$ antenna in India. I then obtained the tender document for the ARVI Satellite Communication Project including the $29.6 \mathrm{~m}$ antenna from the OCS. I had access to several drawings of the structural and mechanical parts of a large parabolic dish antenna. Using these, I and S. S. Bhave from TIFR, Colonel Pant from PRL and a senior engineer of the Tata Consulting Engineers visited several firms in Mumbai: Richardson and Cruddas, Larsen \& Toubro, New Standard Engineering Company and a few others. We concluded that $29.6 \mathrm{~m}$ antenna could be manufactured in Mumbai, installed at ARVI and made operational within 15 months. Sarabhai got approval of Mrs Gandhi for the antenna to be made in India by the DAE. Sarabhai negotiated the purchase of drawings of the $29.6 \mathrm{~m}$ antenna from the RCA Canada who had quoted to OCS for its supply and installation at ARVI in India. Several electronic parts required for the project were imported from Canada. Sometime later Sarabhai phoned me that he would be meeting Sumant Moolgaonkar, Chairman of TISCO at Jamshedpur, at a lunch and asked me to submit a note regarding essential qualifications of the Project Engineer for the $29.6 \mathrm{~m}$ antenna. In the note I wrote that the Project Engineer for the $29.6 \mathrm{~m}$ antenna should have worked on the floor of a workshop for several years before reaching a senior position. After discussions with Sarabhai, Moolgaonkar released N. K. Ghosh who was the Head of the General Engineering Division at TISCO. He was then appointed by the DAE as the Project Engineer for the $29.6 \mathrm{~m}$ antenna project. He ensured fabrication of the $29.6 \mathrm{~m}$ antenna to the required accuracy and its installation at ARVI within 15 months by the New Standard Engineering Company. I made contributions to the manufacturing of antenna panels to sub$\mathrm{mm}$ accuracy as required for the antenna to operate at microwave frequencies. Sarabhai appointed Wg. Cdr. K. R. Rao as the Chairman of the team for the management and installation of the ARVI Satellite and Communication Earth Station at ARVI. The Earth Station for satellite communication to other countries at ARVI was completed in January 1971. At that time India became the fifth nation in the world who had installed Earth Stations for broadband satellite communications to far away countries. Before that only narrowband communication was done at several $\mathrm{MHz}$ that was reflected by the ionosphere and therefore had very limited range.

Seldom is a person born that makes unique contributions to his country. Sarabhai was such a person. He established many institutions in India of considerable importance. Soon after the launching of Sputnik by USSR in 1957, USA and USSR launched many satellites for space communications. Thereafter Sarabhai conceived manufacturing the required equipment for space communications and research in India. Step by step he organized teams that have resulted in the great capabilities of ISRO today. Sarabhai was not only a great scientist but also a very kind and gentle human being.

doi: $10.18520 / \mathrm{cs} / \mathrm{v} 118 / \mathrm{i} 8 / 1188-1189$ 